\title{
Additive Models Reveal Sources of Metals and Organic Pollutants in Norwegian Marine Sediments
}

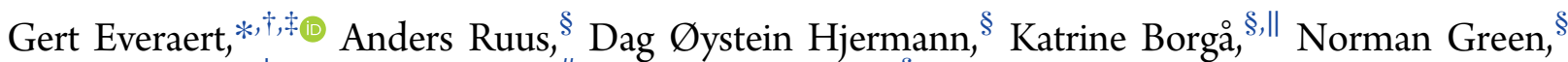 \\ Stepan Boitsov, ${ }^{\perp}$ Henning Jensen, ${ }^{\#}$ and Amanda Poste ${ }^{\S}$ \\ ${ }^{\dagger}$ Department of Applied Ecology and Environmental Biology, Ghent University, 9000 Ghent, Belgium \\ ${ }^{\ddagger}$ Flanders Marine Institute, 8400 Ostend, Belgium \\ ${ }^{\S}$ Norwegian Institute for Water Research, NO-0349 Oslo, Norway \\ "Department of Biosciences, University of Oslo, NO-0316 Oslo, Norway \\ ${ }^{\perp}$ Institute of Marine Research, 5817 Bergen, Norway \\ ${ }^{\#}$ Geological Survey of Norway, NO-7491 Trondheim, Norway
}

Supporting Information

\begin{abstract}
We characterized spatial patterns of surface sediment concentrations of seven polychlorinated biphenyls (PCBs), seven polycyclic aromatic hydrocarbons (PAHs), three chlorinated pesticides, and five metals in Norwegian waters and Skagerrak. In total, we analyzed 5036 concentrations of 22 chemical substances that were measured between 1986 and 2014 at 333 sampling sites by means of generalized additive models (GAMs). We found that GAMs with organic carbon content of the sediment and latitude and longitude as co-variates explained as ca. $75 \%$ of the variability of the contaminant sediment concentrations. For metals, a predominantly hotspotdriven spatial pattern was found, i.e., we identified historical pollution hotspots (e.g., Sørfjord in western Norway) for mercury, zinc, cadmium, and lead. Highest concentrations of PAHs and PCBs were found close to densely populated and industrialized regions, i.e., in the North Sea and in the Kattegat and Skagerrak. The spatial pattern of the PCBs suggests the secondary and diffuse atmospheric nature of their sources. Atmospheric inputs are the main sources of pollution for most organic chemicals considered, but north of the Arctic circle, we found that concentrations of PAHs increased from south to north most likely related to a combination of coal-eroding bedrock and the biological pump. The knowledge acquired in the present research is essential for developing effective remediation strategies that are consistent with international conventions on pollution control.
\end{abstract}

\section{INTRODUCTION}

In the 1970s, it became evident that anthropogenic chemicals can remain in the environment for long periods and pose toxic risk to humans and wildlife. ${ }^{1}$ As a result, multiple international conventions and management programmes were initiated, such as the European Water Framework Directive (Directive 2000/ $60 / \mathrm{EC}$ ), ${ }^{2}$ the Marine Strategy Framework Directive (Directive 2008/56/EC), ${ }^{3}$ the Oslo-Paris Convention for the Protection of the Marine Environment of the North-East Atlantic $(\text { OSPAR })^{1}$ and the Helsinki Convention (HELCOM) that pertains to the Baltic Sea. ${ }^{4}$ These conventions aim to prevent pollution by continuously reducing discharges, emissions and losses of hazardous chemicals to the environment with the ultimate goal of achieving concentrations in the marine environment that are near background values for naturally occurring chemicals and are close to zero for man-made synthetic chemicals. ${ }^{1,5}$ The OSPAR convention provides a framework for frequent and obligatory monitoring to assess the inputs, levels, trends and effects of prioritized contaminants such as polychlorinated biphenyls (PCBs), polycyclic aromatic hydrocarbons (PAHs), pesticides and metals. The results of these monitoring campaigns over time indicate that most of the primary sources and discharges of these priority chemicals have been discontinued or considerably reduced.,7 However, because many chemicals are persistent and strongly particleassociated, contaminated sediments may still act as important secondary pollution sources mainly in coastal waters. ${ }^{8}$ After decades of primary emissions, considerable reservoirs of anthropogenic chemicals have accumulated in sediments. These reservoirs can be remobilized due to climate-induced changes in temperature and organic matter content ${ }^{9}$ or physical disturbances due to sand or gravel extractions and dredging activities. ${ }^{10}$ The latter means that, especially in coastal waters, sediments have shifted from being a sink of pollution to being a potential source of pollution. ${ }^{11,12}$ The terrestrial environment

Received: June 9, 2017

Revised: October 13, 2017

Accepted: October 16, 2017

Published: October 16, 2017 
(e.g., boreal soils, forests, and melting glaciers) can also act as an important secondary source of contaminants, ${ }^{13-15}$ especially in coastal zones, where mobilization of contaminants from upstream catchments can lead to substantial delivery of contaminants (by rivers and diffuse runoff). ${ }^{16}$ Because secondary sources modulate the concentrations of legacy persistent organic pollutants (POPs) in the environment, continued monitoring and assessment of these chemicals is needed.

The Norwegian marine environment receives input of hazardous chemicals due to on- and offshore point sources and diffuse pollution. ${ }^{17}$ Several sites along the Norwegian coast have previously been identified as highly contaminated with organic contaminants and metals. ${ }^{18-20}$ Some of these chemicals are known for their toxic potential and may cause adverse ecological effects. Prior to defining the most appropriate remediation strategy, and in the scope of the above-mentioned conventions and management plans, an important first step is to analyze and quantify the pollution levels, profiles, and time trends in the sediment fraction. In addition, knowledge about the sources of the chemicals, i.e., either primary or secondary sources, is indispendable in the decision making process. Because knowledge about the spatial pattern of the level of chemical pollution in Norwegian marine sediments is essential, in the present study, we assembled one of the largest and most complete databases integrating data from different Norwegian institutes covering the Norwegian marine waters and the Skagerrak region. Based on these data, we assessed the spatial patterns of the contaminant concentrations and aimed to relate these patterns to the main sources of pollution, i.e., natural sources, local industry and mining, or diffuse long-range transport.

\section{MATERIALS AND METHODS}

Data. The Norwegian Institute for Water Research (NIVA), the Institute of Marine Research (IMR), and the Geological Survey of Norway (NGU) have collected a long series of comprehensive marine biological, oceanographic, and contaminants field data. Concentrations of anthropogenic chemicals in Norwegian coastal and marine sediments were obtained from the Marine AREA database for Norwegian waters (MAREANO; Barents Sea and Norwegian Sea) mapping program and the Contaminants in Coastal Waters of Norway monitoring program (MILKYS; North Sea and other coastal waters), which is part of the Norwegian contribution to OSPAR's Coordinated Environmental Monitoring Programme (CEMP).

The main advantage of using field data for sediment (as opposed to sampling the water column) is that concentrations found in this compartment represent exposure over time (e.g., weeks, months, or years) as the sediment integrates the historic pollution signal. In total, 30488 concentrations at 420 sampling locations representing 22 chemicals were extracted from the databases. Based on the reported latitude and longitude, each sampling site was attributed to a geographical category (i.e., inner fjord, coastal, northern offshore, and southern offshore). Samples taken in fjords and bays were categorized as "inner fjord". Samples taken at open sea but close to the mainland were categorized as coastal. All other samples were classified as offshore; those above $66{ }^{\circ} \mathrm{N}$ were classified as northern offshore, and those below $66{ }^{\circ} \mathrm{N}$ were classified as southern offshore (Figure S1). Note that, except for a small number of sampling locations, all data have been collected on the Norwegian Continental Shelf (Figure S2-S4). For data exploration, the sediment concentrations were plotted against the above-mentioned geographical categories for each chemical.

We used a Kruskal-Wallis statistical test and a posthoc Mann-Whitney $U$ test to identify pairwise differences of the chemical concentrations between the four geographical categories. Chemicals included in the analysis are polychlorinated biphenyl 28 (PCB28), PCB52, PCB101, PCB118, PCB138, PCB153, PCB180, $p, p^{\prime}$-dichlorodiphenyltrichloroethane (DDTPP), hexachlorobenzene (HCB), $\alpha$-hexachlorocyclohexane $(\alpha-\mathrm{HCH})$, anthracene (ANT), benz $[a]$ anthracene (BAA), benzo[a]pyrene (BAP), naphthalene (NAP), fluorene (FLU), phenanthrene (PHE), pyrene (PYR), mercury (Hg), cadmium $(\mathrm{Cd})$, zinc $(\mathrm{Zn})$, lead $(\mathrm{Pb})$, nickel $(\mathrm{Ni})$, and total organic carbon (TOC).

Prior to the modeling, three preprocessing steps were performed. First, we only selected samples from the sediment surface layer $(0-1 \mathrm{~cm})$ of the sediment fraction smaller than $2000 \mu \mathrm{m}$ grain size. Next, if one site was sampled multiple times in the same year, we calculated the average concentration. For example, at sampling location $10 \mathrm{~S}$ in Varangerfjorden $\left(69^{\circ} 56^{\prime} 06^{\prime \prime} \mathrm{N}\right.$; $\left.30^{\circ} 06^{\prime} 42^{\prime \prime} \mathrm{E}\right)$ concentrations of mercury have been quantified three times in the top layer of the sediment (i.e., 0.053; 0.043; and $0.052 \mathrm{mg} \mathrm{kg}^{-1}$ dry weight) in 1994 . Hence, we calculated the average contaminant concentration (0.049 $\mathrm{mg} \mathrm{kg}^{-1}$ dry weight) and used this in the further analysis. The selection of the sediment surface layer combined with the year-round averaging resulted in a data set composed of 5036 records representing yearly average sediment concentrations measured between 1986 and 2014 (Table S1) at 333 sampling sites (Figure S2-S4). Furthermore, in line with the approach of Borga et al. (2011), ${ }^{21}$ if the reported concentrations were below the limit of quantification, we replaced the concentration (e.g., $<0.05 \mu \mathrm{g} \mathrm{kg}^{-1}$ ) by a random value. This random value was selected from a uniform distribution characterized by half of the limit of quantification (minimum value; e.g., $0.025 \mu \mathrm{g} \mathrm{kg} \mathrm{kg}^{-1}$ ) and the limit of quantification (maximum value; e.g., $0.05 \mu \mathrm{g} \mathrm{kg}^{-1}$ ). A chemical-specific summary of the data set is available in Table S1.

Model. The overall objective of the present research was to infer spatial patterns of anthropogenic chemicals in marine sediments in Norwegian waters and to relate these patterns to different potential pollution sources. A main advantage of using field data is that the natural background variation of marine ecosystems (e.g., seasonal variation) is implicitly included in the results that are obtained. However, field studies may be subject to perturbations that affect the bioavailability of organic chemicals. $^{22}$ In this context, statistical ecological modeling can be useful to quantify the impact of the natural variability on the ambient concentrations of contaminants. To do so, we opted for generalized additive models (GAMs) because of their ability to simultaniously capture the linear and non linear effects of variables. ${ }^{23}$ Additive modeling is a nonparametric alternative to the more conventionally used generalized linear models (GLMs). GAMs only differ from GLMs in that GAMs use nonparametric smooth functions of the co-variates, whereas GLMs use products between the regression coefficients and the co-variate. ${ }^{23}$ As such, GAMs can, as a data mining method, disentangle additive effects of different predictor variables on the response variables from the data without making strong assumptions about the shape of the response function. ${ }^{24,25}$ The GAM regression technique consists of fitting smooth additive functons for each co-variate included in the model structure. 
Table 1. Summary of the Chemical-Specific Generalized Additive Models ${ }^{a}$

\begin{tabular}{|c|c|c|c|c|c|c|c|}
\hline & $n$ & TOC & longitude and latitude & AIC & $R^{2}$ & deviance explained & figure \\
\hline $\mathrm{Hg}$ & 362 & $1.4 \times 10^{-15}$ & $<2.0 \times 10^{-16}$ & 94.1 & 0.70 & $72.1 \%$ & Figure S12 \\
\hline $\mathrm{Cd}$ & 362 & $7.3 \times 10^{-11}$ & $2.7 \times 10^{-16}$ & 160.6 & 0.41 & $45.7 \%$ & Figure S13 \\
\hline $\mathrm{Ni}$ & 322 & $<2.0 \times 10^{-16}$ & $<2.0 \times 10^{-16}$ & -345.5 & 0.76 & $78.0 \%$ & Figure S14 \\
\hline $\mathrm{Pb}$ & 362 & $<2.0 \times 10^{-16}$ & $<2.0 \times 10^{-16}$ & -149.6 & 0.73 & $74.8 \%$ & Figure S15 \\
\hline $\mathrm{Zn}$ & 362 & $<2.0 \times 10^{-16}$ & $<2.0 \times 10^{-16}$ & -302.4 & 0.81 & $82.5 \%$ & Figure S16 \\
\hline NAP & 243 & $<2.0 \times 10^{-16}$ & $<2.0 \times 10^{-16}$ & 37.9 & 0.77 & $79.6 \%$ & Figure S21 \\
\hline FLU & 242 & $<2.0 \times 10^{-16}$ & $<2.0 \times 10^{-16}$ & 132.0 & 0.84 & $85.7 \%$ & Figure S22 \\
\hline PHE & 243 & $<2.0 \times 10^{-16}$ & $<2.0 \times 10^{-16}$ & 8.1 & 0.84 & $85.7 \%$ & Figure S23 \\
\hline ANT & 241 & $<2.0 \times 10^{-16}$ & $<2.0 \times 10^{-16}$ & 53.8 & 0.84 & $85.4 \%$ & Figure $\mathrm{S} 18$ \\
\hline PYR & 243 & $<2.0 \times 10^{-16}$ & $<2.0 \times 10^{-16}$ & -39.4 & 0.86 & $87.3 \%$ & Figure S24 \\
\hline BAA & 243 & $<2.0 \times 10^{-16}$ & $<2.0 \times 10^{-16}$ & 8.0 & 0.80 & $81.7 \%$ & Figure S19 \\
\hline BAP & 243 & $<2.0 \times 10^{-16}$ & $<2.0 \times 10^{-16}$ & 86.1 & 0.74 & $76.9 \%$ & Figure S20 \\
\hline$\sum_{7} \mathrm{PAH}$ & 241 & $<2.0 \times 10^{-16}$ & $<2.0 \times 10^{-16}$ & -58.6 & 0.85 & $86.5 \%$ & Figure S17 \\
\hline РCB28 & 113 & $1.9 \times 10^{-12}$ & $1.4 \times 10^{-8}$ & 25.1 & 0.80 & $84.2 \%$ & Figure S26 \\
\hline PCB52 & 113 & $1.6 \times 10^{-13}$ & $6.9 \times 10^{-5}$ & -22.1 & 0.79 & $83.9 \%$ & Figure S27 \\
\hline PCB101 & 113 & $<2.0 \times 10^{-16}$ & $1.3 \times 10^{-3}$ & 22.5 & 0.73 & $75.0 \%$ & Figure S28 \\
\hline PCB118 & 113 & $<2.0 \times 10^{-16}$ & $8.8 \times 10^{-6}$ & 0.1 & 0.78 & $79.9 \%$ & Figure S29 \\
\hline PCB138 & 113 & $<2.0 \times 10^{-16}$ & $2.4 \times 10^{-5}$ & 17.3 & 0.74 & $75.4 \%$ & Figure S30 \\
\hline PCB153 & 91 & $<2.0 \times 10^{-16}$ & $3.7 \times 10^{-6}$ & 6.7 & 0.80 & $81.7 \%$ & Figure S31 \\
\hline PCB180 & 113 & $<2.0 \times 10^{-16}$ & $2.1 \times 10^{-1}$ & 99.2 & 0.52 & $53.7 \%$ & Figure S32 \\
\hline$\sum_{7} \mathrm{PCB}$ & 91 & $<2.0 \times 10^{-16}$ & $<2.0 \times 10^{-16}$ & 10.3 & 0.84 & $85.3 \%$ & Figure S25 \\
\hline DDTPP & 96 & $9.3 \times 10^{-9}$ & $1.8 \times 10^{-4}$ & 91.7 & 0.71 & $77.2 \%$ & Figure S34 \\
\hline $\mathrm{HCB}$ & 113 & $7.0 \times 10^{-14}$ & $5.4 \times 10^{-3}$ & 60.4 & 0.69 & $72.0 \%$ & Figure S35 \\
\hline$\alpha-\mathrm{HCH}$ & 113 & $1.7 \times 10^{-8}$ & $1.6 \times 10^{-8}$ & 65.9 & 0.71 & $76.1 \%$ & Figure S33 \\
\hline
\end{tabular}

${ }^{a}$ Each model included the total organic carbon content of the sediment (TOC) and an interaction term between latitude and longitude (eq 1). The $p$-values are reported to indicate the contribution of the co-variates to the model. Models were chemical-specific and based on a number of samples $(n)$. They were assessed based on the Akaike Information Criterion (AIC), the adjusted correlation coefficient $\left(R^{2}\right)$, and residual diagnostics (Figures S7-S10). We characterized the spatial concentration of the following chemicals: polychlorinated biphenyl 28 (PCB28); PCB52; PCB101; PCB118; PCB138; PCB153; PCB180; $p, p^{\prime}$-dichlorodiphenyltrichloroethane (DDTPP); hexachlorobenzene (HCB); $\alpha$-hexachlorocyclohexane $(\alpha$-HCH); anthracene (ANT); benz $[a]$ anthracene (BAA); benzo $[a]$ pyrene (BAP); naphthalene (NAP); fluorene (FLU); phenanthrene (PHE); pyrene (PYR); mercury $(\mathrm{Hg})$; cadmium $(\mathrm{Cd})$; zinc $(\mathrm{Zn})$; lead $(\mathrm{Pb})$; nickel $(\mathrm{Ni})$; the sum of seven polycyclic aromatic hydrocarbons $\left(\sum_{7} \mathrm{PAH}\right)$; and the sum of seven polychlorinated biphenyls $\left(\sum_{7} \mathrm{PCB}\right)$.

These smooth functions are linear combinations of a finite number of cubic spline functions, with the smoothness of the function estimated by balancing between the model fit and the model complexity. ${ }^{23}$

In ecological research, GAMs have been often used. For example, Stenseth et al. $(2006)^{26}$ used GAMs to study seasonal plankton dynamics under a complex scenario of physical and biogeochemical variability. More recently, Feng et al. $(2015)^{25}$ used GAMs to analyze large-scale satellite derived data to characterize correlation patterns between environmental forcing and marine biomass. Furthermore, GAMs have been used to assess the risks of agricultural pesticides in small streams in Germany, ${ }^{27}$ to model the spatial distribution of deep-sea coral, $^{28}$ to map the distribution of Baltic Sea flounder, ${ }^{29}$ and to infer trends from pollution data. ${ }^{7,30}$ In the present research, the chemical-specific GAMs incorporated TOC and geo-spatial information as:

$$
\begin{aligned}
\left.\log _{10}([\text { chemical }]]\right)= & b_{x}+f_{1, x}([\text { TOC }]) \\
& +f_{2, x}(\text { latitude, longitude })+\varepsilon_{x}
\end{aligned}
$$

where $[$ chemical $\mathrm{X}]$ is the concentration of chemical $\mathrm{X}$ measured at different locations in Norwegian marine waters. A chemical-specific intercept is $b_{x}$, and $f_{i, x}(i=1$ or 2$)$ are chemical-specific smooth functions (cubic splines with a maximum of four degrees of freedom for TOC; $\left.f_{1, \mathrm{x}}\right)$ describing the partial additive effect of the predictor variable on the chemical concentrations. We included a smooth function on the interaction effect between latitude and longitude $\left(f_{2, \mathrm{x}}\right)$ to capture the geo-spatial variability of the concentration of chemical X. A chemical-specific normal distribution and independent noise term is $\varepsilon_{x}$ (eq 1 ).

Model selection was based on the residual diagnostics as in Zuur et al. (2009). ${ }^{31}$ Homogeneity was concluded if the variability of the residuals was similar across the range of fitted values. One model was built for each chemical (22 in total) and for the sum of seven PCBs (i.e., PCB28, PCB52, PCB101, PCB118, PCB138, PCB153, and PCB180) and of seven PAHs (i.e., ANT, BAA, BAP, NAP, FLU, PHE, and PYR). Normality was assessed using a quantile-quantile plot and a histogram of the model residuals. ${ }^{23}$ For each of these chemical-specific models, we report the amount of deviance explained, the Akaike Information Criterion (AIC), and the significance level of the covariates (Table 1). The spatial pattern of each chemical was deduced directly from the latitude--longitude interaction term.

Meta-Analysis. The chemical-specific models (as described in the previous paragraph) were used to perform a metaanalysis to investigate which type of pollution (i.e., primary or secondary sources) was driving the environmental fate of the organic chemicals (i.e., PAHs, PCBs and pesticides). To do so, for each hydrophobic chemical we extracted the corresponding intercept $\left(b_{x}\right)$ of the additive model and plotted these chemicalspecific intercepts (17 in total) against the corresponding $\log _{10}$ organic carbon-water partition coefficients $\left(\log \mathrm{K}_{\mathrm{OC}}\right)$ and the corresponding molecular weights (MW). For five metals, the 

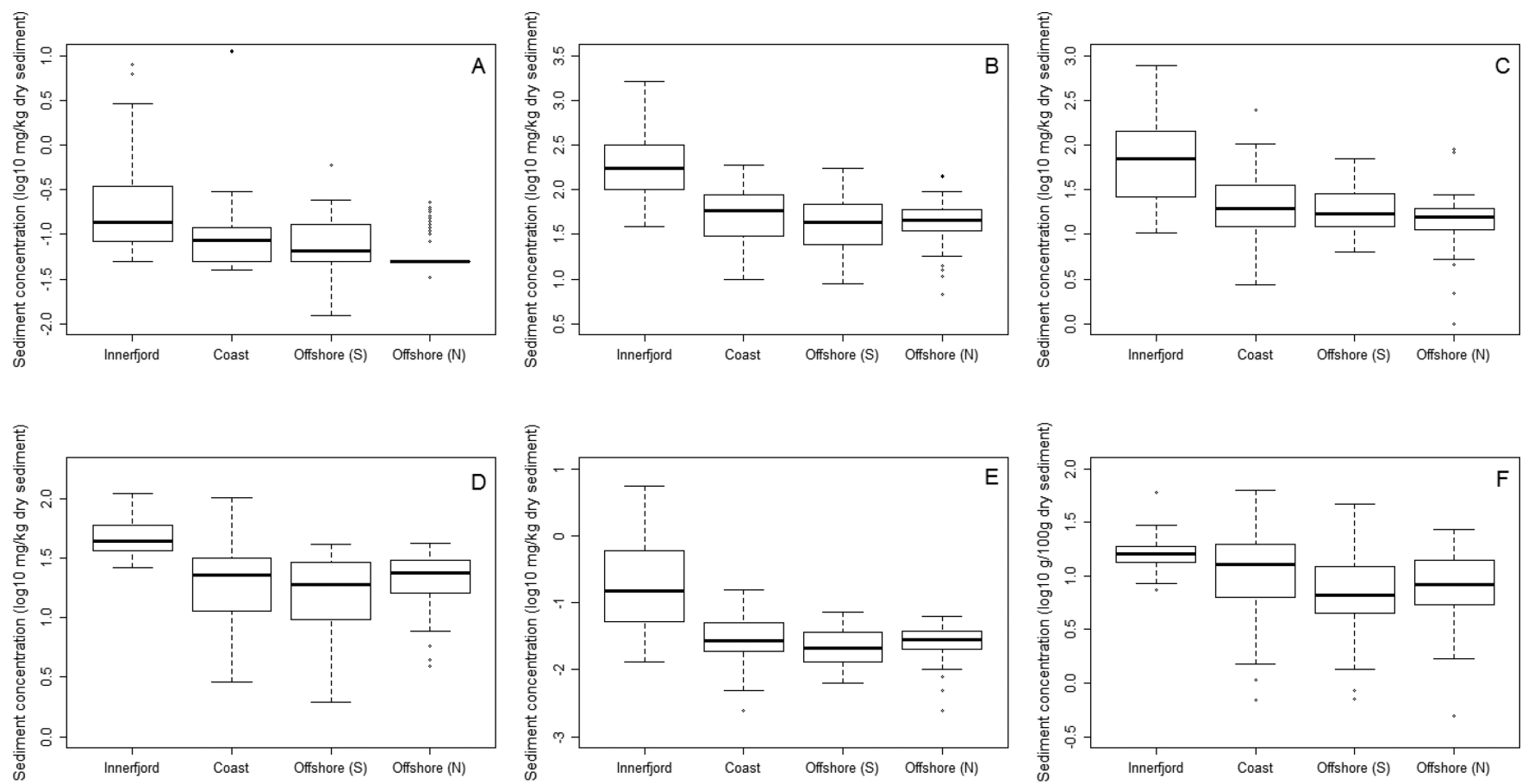

Figure 1. Surface-sediment concentrations of cadmium (A), zinc (B), lead (C), nickel (D), mercury (E), and total organic carbon (F) divided according to the geographical location of the sampling sites. Each sampling site was attributed to a geographical category (i.e., innerfjord, coastal, offshore (North), and offshore (South)). Samples taken inside fjords and bays were categorized as "innerfjord". Samples taken at open sea but close to the main land were categorized as coastal. All other samples were classified as offshore, those above $66^{\circ} \mathrm{N}$ were considered northern offshore, and those below $66^{\circ} \mathrm{N}$ were considered southern offshore.

same extraction was done as for the organic chemicals and the chemical-specific intercepts were plotted against the corresponding MW. The intercept of an additive model is a first indication of the magnitude of the concentrations, i.e., the higher the intercept, the higher the concentration of the corresponding chemical. If primary point sources have a dominant impact on the observed concentrations, then it is hypothesized that no clear relationship is found between the intercepts and $\mathrm{K}_{\mathrm{OC}}$ or $\mathrm{MW}$ as this suggests that the chemicals present in the different environmental compartments are not yet in equilibrium. Hence, we hypothesize that, in case of primary sources, no clear relation will be found between the chemical-specific intercepts against the corresponding log $K_{\mathrm{OC}}$ and MW. However, if secondary sources dominate the concentrations of the chemicals, then clear intercept $-K_{\mathrm{OC}}$ and intercept-MW relationships are expected across chemicals that belong to the same group (i.e., PAHs, PCBs, and pesticides). This type of meta-analysis is similar to the approach followed by Everaert et al. (2014) and Berrojalbiz et al. (2011). ${ }^{7,32}$ All statistical analyses were performed in $\mathrm{R}$, and the additive models were fitted with the $m g c v$ library. ${ }^{33}$

\section{RESULTS AND DISCUSSION}

Data Exploration. The sediment concentration of metals, chlorinated compounds, and PAHs were dependent on the sampling site (Figures 1and S5-S6 and Table S2). Median concentrations of heavy metals were on average 2- to 4-fold higher inside fjords than in offshore sampling locations $(p<1.8$ $\times 10^{-8}$; Figure 1 ; Table S3-S7). For PAHs, we found that median concentrations of NAP, PHE, and BAP were not significantly different at the four geographical sampling locations $(p>0.20$; Figure S6). However, concentrations of BAA, ANT, FLU, and PYR and of the chlorinated compounds were higher in fjords than in offshore sampling sites $(p<0.04$; Table S8-S26). For example, in the inner fjord sampling locations median concentrations of ANT were 2.11 (first quartile $=1.57$; third quartile $=6.95) \mu \mathrm{g} \mathrm{kg}^{-1}$ dry sediment. In the southern offshore sampling locations ANT concentrations were about three times lower (i.e., $0.76(0.40-1.43) \mu \mathrm{g} \mathrm{kg}^{-1}$ dry sediment; $p=9.0 \times 10^{-3}$; Table S2). Similar differences were found for $\mathrm{PCB} 28$, i.e., median concentrations in inner fjord sampling locations were $0.16(0.14-0.36) \mu \mathrm{g} \mathrm{kg}^{-1}$ dry sediment, which is about 5-fold higher than in southern offshore sampling locations with median concentrations of 0.03 $(0.02-0.09) \mu \mathrm{g} \mathrm{kg}^{-1}$ dry sediment (Table S2). It is important to note that for some specific PAHs (e.g., PHE and NAP) median relatively high concentrations were found in northern offshore sampling sites at levels that are comparable or even higher than the concentrations observed in coastal sampling locations (Table S2 and Figure S6).

Although we acknowledge that it is compound-specific, overall, we found on average 2- to 4-fold higher concentrations of chemicals close to urbanized and industrialized sites than in rural less-populated areas. This pattern is likely to be related with point sources inside the fjords and diffuse catchment inputs paired with the fjord hydrology (see further). In addition, TOC is considerably higher in fjords (i.e., 17.2 (13.8-

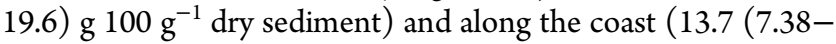

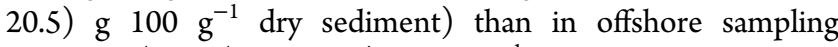
locations (6.54 (3.47-12.4) g $100 \mathrm{~g}^{-1}$ dry sediment and 7.98 (5.35-12.4) g $100 \mathrm{~g}^{-1}$ dry sediment; Table S2 and S27 and Figure $1 \mathrm{~F}$ ), hence resulting in higher binding capacities of the sediment for chemicals. These findings corroborate with those of Everaert et al. $(2014)^{7}$ in the North Sea and GomezGutierrez et al. $(2007)^{34}$ in the Mediterranean Sea. 

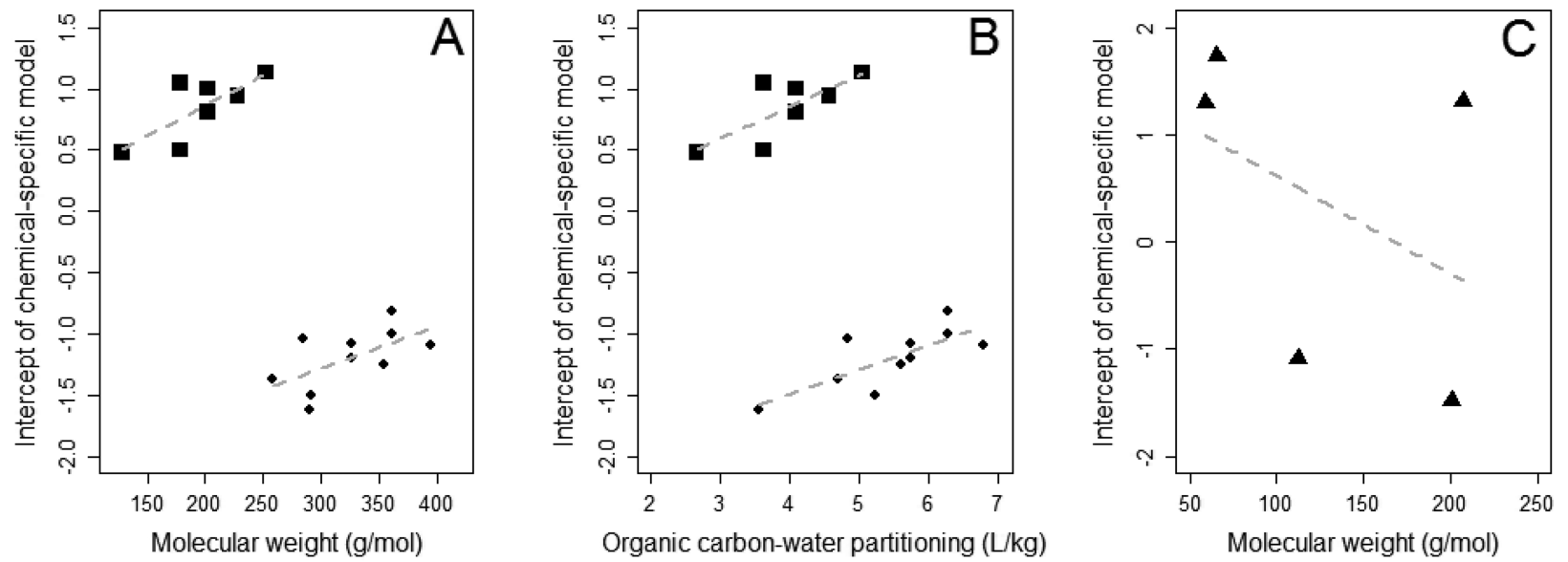

Figure 2. Intercepts of the chemical specific intercepts of the generalized additive model plotted against the corresponding molecular weights of the organic chemicals (panel A) and the organic carbon-water partitioning coefficient of the organic chemicals $\left(\log K_{\mathrm{OC}}\right.$; panel B). Intercepts of the chemical specific intercepts of the generalized additive model plotted against the corresponding molecular weights of the metals (panel C). Analysis is performed for chlorinated chemicals (circles), polycyclic aromatic hydrocarbons (squares), and metals (triangles). For each group of chemicals, we added a gray trend line. The correlation coefficients in panel A are $0.76(p=0.048)$ and $0.60(p=0.067)$ for PAHs and PCBs, respectively. The correlation coefficients in panel B are $0.75(p=0.047)$ and $0.75(p=0.012)$ for PAHs and PCBs, respectively. The correlation coefficient in panel C is $-0.43(p=0.469)$ for metals.

Chemical-Specific Models. GAMs with TOC and an interaction term between latitude and longitude as co-variates explained about $75 \%$ of the variability of the log-transformed sediment concentrations (Table 1). However, for cadmium, the variability explained was only $45.7 \%$. The latter is related to the concentrations that were reported as $0.05 \mu \mathrm{g} \mathrm{kg}^{-1}$ dry weight, which was the limit of quantification. Based on the straight line of residuals in the residual plots (Figure S7), we suspect that most of those concentrations were close to, but different from, the limit of quantification of cadmium. For all other chemicals under study, the residuals of the models were randomly distributed, followed a normal distribution and the predicted values plotted against the observed values were on a straight line parallel with the first diagonal (Figures S7-S10). Because the residuals do not show a particular pattern or bias the models are valid and useful to infer the chemical-specific spatial trends. Furthermore, the meta-analysis of the intercepts will give valuable information on the nature of the sources of pollution (as explained in the rationale of the methodological section). For all the chemicals tested, we found a significant positive relationship between the TOC and the sediment concentrations of the chemical $\left(p<1.7 \times 10^{-8}\right.$; Table 1; Figure S11). As such, GAMs including TOC as a co-variate do take into account the spatial gradient of TOC (Figure 1F). This finding is in line with Ma et al. (2015), ${ }^{35}$ who found a positive correlation between the concentration of POPs and TOC in marine sediments. Indeed, many POPs are hydrophobic (log $K_{\text {ow }}>5$ ) and have an affinity for fatty tissues and organic material. ${ }^{36,37}$ As for POPs, metals showed a clear affinity for marine sediments with relatively high content of TOC $(p<7.3$ $\times 10^{-11}$; Table 1$)$, corroborating with the results of Palanques et al. $(1995)^{38}$ in the Gulf of Cadiz (Spain). Except for PCB180 $\left(p=2.1 \times 10^{-1}\right.$; Table 1$)$, the smoother of the interaction term between longitude and latitude of the sampling locations contributed in each model $\left(p<1.3 \times 10^{-3}\right.$; Table 1$)$.

Spatial Patterns and Sources. The interaction term between longitude and latitude was an important contributor to fit of the chemical-specific models (Table 1) and revealed the spatial patterns of the concentrations of the chemicals as it quantified the nonlinear influence of the position of the sampling location on the chemical concentrations. Dissimilar spatial patterns and sources were found for each group of chemicals. In the meta-analysis of the chemical-specific models (Figure 2A-C), we found a clear relationship between the chemical-specific intercept and the corresponding MW and log $K_{\mathrm{OC}}$. For both PAHs and PCBs, we found a linear trend between the intercept and the MW $(r=0.60$ and $r=0.76$, respectively) and between the intercept and the $\log K_{\mathrm{OC}}(r=$ 0.75 and $r=0.76$, respectively) (Figure 2A - 2B). The latter suggests that mainly secondary sources contribute to the fate of the organic chemicals as the magnitude of the chemical-specific intercepts show a relationship (suggesting equilibrium conditions) with the chemical characteristics of the substances (see further resources). ${ }^{7}$ For metals, in spite of the fact that the amount of TOC plays an important role in their concentrations, i.e., the more TOC, the higher the concentrations of metals $\left(p<7.3 \times 10^{-11}\right.$; Table 1$)$, the meta-analysis showed no uniform relation between the MWs and the intercepts of the chemical-specific models (Figure 2C). Because there was no clear relationship between the intercepts and the corresponding MWs (Figure 2C), it is suggested that mainly direct primary sources contribute to their environmental concentrations. Indeed, for metals a predominantly hotspot driven spatial pattern was found (Figures S12-S16), with higher than average metal concentrations in fjords and bays (Figure 1). Both natural factors (i.e., metal rich ores or bedrock in combination with erosion) ${ }^{39}$ as well as anthropogenic sources (i.e., mining and metal industries $)^{40}$ are hypothesized to contribute to the elevated metal concentrations at particular sites. Among the anthropogenic sources, we count the hydroelectric power plants that were installed and energy-demanding industries like smelters and metallurgical plants that were developed in the past century. ${ }^{20}$ Prior to (inter)national legislation, untreated waste products from these industries were often discharged directly into the marine environment. ${ }^{41}$ Fjords often have a shallow sill near the mouth that limits water exchange with open marine waters, resulting in longer water retention times in fjords than in open waters. ${ }^{42}$ As such, recipient waters from a 
point-discharge within a fjord might have a relatively high contaminant concentration (either in the dissolved phase or associated with particles) that can persist for a long time and increase contaminant loading to bottom sediments. ${ }^{41,43}$ In addition, contaminants delivered by rivers and freshwater runoff are also affected by the "salting out" phenomenon, whereby increased salinity in receiving fjord waters causes increased partitioning of contaminants into the particulate phase, which can lead to enhanced sedimentation of these contaminants. ${ }^{44}$ For several metals, such as mercury (Figure S12), cadmium (Figure S13), lead (Figure S15), and zinc (Figure S16) the most dominant feature of the spatial pattern is a hotspot in Sørfjorden (in western Norway), where there has been important local input from a zinc smelter. ${ }^{18,19}$ In Sørfjorden, the jarosite waste of metallurgic activities was discharged in the fjord until 1986 and was long-considered to be one of the most metal-polluted fjords in the world. ${ }^{18}$ It appears that the metal pollution in this region mainly originates from (historical) primary sources and is still residing in the sediment of the corresponding fjords and bays. A study by Temara et al. $(1998)^{45}$ found that within Sørfjorden, concentrations of lead, cadmium, and zinc were consistently higher (1.7 to 8.3 times) in the brittle star Asterias rubens sampled close to the smelter than in those sampled further away. Remedial actions in Sørfjorden have included the disposal of metal-containing sludge in mountain caverns and the containment of contaminated sediment by the use of sheet pilings or capping. Highest concentrations of nickel have been found along the northern part of the Norwegian coast (Figure S14), corroborating the findings of Reimann et al. (2000) and Sandager et al. (2011).46,47 and in offshore sampling locations northwest of Trondheim, where there is an important deposition zone of suspended solids to the sediments (Figures S13-S14). ${ }^{39}$ In other regions, such as for example the Trondheim fjord, Faust et al. (2014) ${ }^{39}$ have demonstrated the importance of greenstone bedrock for the geochemical composition of the surface sediments. In this region, there is evidence that the bedrock is an important natural source for $\mathrm{Zn}$ and $\mathrm{Ni}$. Because $\mathrm{Zn}$ and $\mathrm{Ni}$ are often associated with inorganic fine grain part of the sediment (i.e., clay and silt fractions), ${ }^{48}$ it is likely that the high $\mathrm{Zn}$ and $\mathrm{Ni}$ concentrations in and around the Trondheim fjord mainly originate from a mixture of natural and anthropogenic pollution sources.

Metals such as mercury and lead are more strongly associated with the organic carbon content and have mainly anthropogenic sources (Figure S11). ${ }^{48}$ We identified a pollution hotspot of lead in Sørfjorden, and elevated concentrations of lead in Skagerrak and along the coast of southern Norway. The elevated concentrations in these areas are directly related to the industrial applications of lead and the high degree of human activity. Elevated lead concentrations in southern Norway likely reflect a combination of local and regional inputs as well as long-range inputs from Europe (both historical and current) delivered through atmospheric deposition and rivers/runoff. Some of the organic lead antifouling agents have been manufactured locally, but that is considered to be a minor source. ${ }^{49}$ Hotspots of cadmium were found in Sørfjorden and close to the Lofoten archipelago (Figure S13), which is consistent with the findings of Julshamn et al., ${ }^{50}$ who observed high cadmium concentrations in edible crabs in Vestfjorden. Cadmium is found naturally in minerals and soils and is transported with both water and air, ${ }^{51}$ but cadmium has also been used in various industrial processes such as protecting steel against corrosion. ${ }^{49}$ In 2007 , the emission of cadmium was estimated to 1.4 tons, ${ }^{51}$ with the highest discharges in Sørfjorden, Årdalsfjorden, and Orkdalsfjorden. Furthermore, it was estimated that an additional 3.5 tons of cadmium reach Norway through atmospheric long-range transport, ${ }^{52}$ which mostly affected the southern part of Norway. ${ }^{53}$ In 2009, the emission from closed mines to Norwegian waters were estimated to 0.3 tons and is considered the most-important known point source. In the same year, emissions from 63 industrial plants amounted to a comparable quantity. ${ }^{52}$ Overall, the interpretation of the meta-analysis (Figure 2C), that the concentrations of metals in Norwegian marine waters is mainly driven by primary point-sources and, to a limited extent, by diffuse long-range atmospheric transport, is reflected in their hotspot-like spatial patterns (Figures S12-S16) and is supported by scientific literature.

For the chlorinated pesticides, PCBS, and PAHs mainly diffuse, secondary sources modulate their concentrations because clear intercept-MW (Figure 2A) and intercept-log $\mathrm{K}_{\mathrm{OC}}$ (Figure $2 \mathrm{~B}$ ) relations were found across chemicals that belong to the same group of pollutants. Multiple biogeochemical processes affect the fate of the organic chemicals in the marine environment. ${ }^{54}$ The chemical-specific spatial distributions that were inferred based on the GAMs (Figures S17S35) have evolved over the past years and decades through complex interactions between a myriad of biogeochemical processes. In this context, we identified signs of these biogeochemical processes in the spatial patterns that were inferred, suggesting that they have played a role in the fate of organic chemicals in Norwegian marine sediments. Without having the intention to disentangle the interactions of the biogeochemical processes that were involved (which was not possible based on the models developed in the present research), these signs are discussed below. Overall, we found that mainly secondary and diffuse sources contribute to the fate of the organic chemicals as the magnitude of the chemicalspecific intercepts show a relationship with the chemical characteristics of the substances, suggesting equilibrium conditions (Figure 2A,B).

Between northern Norway (main land) and Svalbard, the concentrations of PAHs gradually increase from south to north (Figures S17-S24). The presence of PAHs here is, first of all, related to diffuse air-water exchange in atmospheric and ocean currents from Central and Western Europe because at these high latitudes, there are few direct anthropogenic sources. ${ }^{54-56}$ In addition to the diffuse pollution via long-range atmospheric and aqueous transport, ${ }^{56}$ the erosion of coal-bearing bedrock also plays an important role (Figures S17-S24). ${ }^{47,58}$ The latter is a natural process and is considered a primary source of PAHs in the region. Furthermore, as the shallow Barents Sea bank (Svalbard Bank) is one of the most productive Arctic seas, ${ }^{59,60}$ the role of the biological pump in the fate of the organic chemicals must be considered. By means of the biological pump mechanism, organic chemicals are taken up by marine phytoplankton, and these plankton-bound chemicals are subsequently transferred to deeper water and sediment. ${ }^{61}$ Especially during, and directly after, the phytoplankton bloom, the flux of organic chemicals to sediment is high. ${ }^{61}$ Note that this process mainly affects PAHs with high MWs and that more than $90 \%$ of the PAHs with two or three aromatic rings that reach the surface water via diffuse air-water exchange are degraded before they reach the sediment. ${ }^{62-64}$ 
As in the present research, both two- and three-ring PAHs as well as high-MW PAHs have elevated concentrations in the region between North Norway and Svalbard, and the impact of coal-eroding bedrock seems more important than the biological pump mechanism. Unfortunately we lack data on the PCB concentrations in this region. These PCB data could have served as an independent validation tool with few authoctonous inputs in this region. Therefore, we hypothesize that the airsediment transport as mediated by the OC settling fluxes (biological pump) are most important for high-MW PAHs and only to a lesser extent for low-MW PAHs for which diffuse airwater exchange and coal-eroding bedrock are expected to be the main sources.

In the southern part of the study area, the highest concentrations of PAHs were observed in the North Sea and the Skagerrak (Figures S17-S24), which relates to continuous diffuse atmospheric inputs from households and industry. ${ }^{41}$ In the North Sea, as of 1969, oil and gas exploitation platforms have been developed in Norwegian marine waters and via sea and wind currents these regions receive considerable inputs of PAHs from these platforms and from Western and Central Europe. In this context, Boitsov et al. $(2013)^{57}$ compared the $\mathrm{PAH}$ composition and sources in the North Sea and Skagerrak (IMR monitoring data) with those of the southwestern part of the Barents Sea (MAREANO data). It was highlighted that pristine areas of the Barents Sea have lower levels of PAHs than the Skagerrak. The elevated PAH levels in the Skagerrak were mainly attributed to a mixture of sources such as extensive offshore petroleum industry in the North Sea, intense ship traffic, larger populations, and industrial activities. ${ }^{57}$

For chlorinated compounds such as PCB28, PCB52, PCB101, PCB118, PCB138, and $\alpha-\mathrm{HCH}$ a gradient, with decreasing concentrations from the Southeast to the Northwest of the study area, was found (Figures S25-S31 and S33). The sediment concentrations of these compounds decreased in parallel to the Norwegian coastline and the highest concentrations were identified in the North Sea and Skagerrak. For the chlorinated compounds, riverine inputs and point sources $^{20,65}$ are most important in fjords and coastal systems (Figure S5). However, for most marine regions, and certainly those located offshore, atmospheric deposition is the main source of pollution with PCBs and chlorinated pesticides. ${ }^{66}$ For these compounds, there are mainly historical sources, ${ }^{67}$ and even though there is long-range transport, this is a slow process historically. Sediments integrate this historical signal, and once the PCBs and chlorinated pesticides are captured in sediments they may not be remobilize, except in shallow areas. In addition, as for PAHs, the transport to sediments due to settling particles (biological pump) will be favored for the more hydrophobic congeners, for example PCB $180 .{ }^{68}$ In this context, it is not unexpected that the spatial pattern of congener PCB180 differs from the other congeners, with low concentrations in the Skagerrak but a clear hotspot close to Varanger in Northwest Norway (Figure S32). It is hypothesized that the PCB180 concentrations in this region are mainly originating from (historical) pollution from Russian smelter activity, ${ }^{47}$ which, in combination with the relatively high productivity of the Barents Sea at the Kola peninsula, ${ }^{60}$ has resulted in elevated concentration of PCB180 in the sediment in this part of the study area (Figure S32).

Relevance for Management. In the meta-analysis of the chemical-specific models (Figure 2), we found a clear relationship between the chemical-specific intercept and the corresponding $\mathrm{MW}$ and $\log K_{\mathrm{OC}}$. The latter suggests that mainly secondary sources contribute to the fate of the organic chemicals as the magnitude of the chemical-specific intercepts show a relationship (suggesting equilibrium conditions) with the chemical characteristics of the substances. ${ }^{7}$ Therefore, in the discussion of which remediation strategy might be most efficient in the long run, decision makers should focus on both local sources and conditions as well as the chemical characteristics of the targeted substances. The main reason to do so is that PAHs and PCBs (and all organic chemical in general) partition between different environmental compartments (i.e., air, water, soil, sediment, and biota) and aim for a mass balance in equilibrium. Cleaning one compartment will not be successful if the remaining compartments can still act as potential sources. Furthermore, local conditions such as ship traffic in harbors may cause propeller-induced erosion and has a negative effect on environmental conditions by exposing and remobilizing sediments from previous decades. ${ }^{69}$ In some cases, severe (historical) pollution capping of the sediment seems to be a good option and has already been shown as successful. ${ }^{70}$ However, urban runoff in Norwegian fjords might also be a small, but significant, contributor to pollution levels. ${ }^{17}$ Although it is clear that selecting the most-optimal remediation strategy is not straightforward, the present research summarizes the pollution levels of 22 priority hazardous substances in the Norwegian marine waters. The overlap of these maps with the quantitative input of chemicals (for example, via urban runoff ${ }^{71}$ or atmospheric deposition $)^{72}$ at the different sites will give policy-makers valuable information with which to select the most-efficient remediation strategy.

Relevance for Monitoring. The present research used 5036 points of data for 22 chemicals sampled between 1986 and 2014 at 333 sampling sites. Despite the size of the database, it is difficult to infer time trends because no locations are sampled on a frequent basis. Few locations were sampled three or four times between 1986 and 2014, and many more were only visited once. Taking into account possible seasonal changes of sediment concentrations ${ }^{61}$ and cyclic interannual changes due to climatic oscillations, ${ }^{7}$ this is too few to characterize the temporal trends of the concentrations. ${ }^{1,2}$ Furthermore, we selected at each sampling location the top 1 $\mathrm{cm}$ layer. However, sedimentation rates may largely vary in our study area, with high sedimentation rates at some locations (e.g., order of magnitude of centimeters per year) and low sedimentation rates in other areas (e.g., the order of magnitude of millimeters per year). The latter means that a slice of sediment of one locations may represent multiple years or even decades, whereas the same slice from other locations may integrate only few years. Hence, caution is needed when inferring time trends from this type of data. ${ }^{35}$ So, in spite of the large integrated data set, unbiased time trends could not be inferred. A potential solution is the use of dated sediment cores, as available in the MAREANO, program that may document past changes in the inputs and concentrations of hazardous substances.

\section{ASSOCIATED CONTENT}

\section{Supporting Information}

The Supporting Information is available free of charge on the ACS Publications Web site at: The Supporting Information is available free of charge on the ACS Publications website at DOI: 10.1021 /acs.est.7b02964. 
Additional information including an overview of the original data set and of the data set after preprocessing; median concentrations of 22 substances categorized per geographical area, tables showing the nonparameteric Kruskal-Wallis statistical tests for each substance, maps showing the locations and depths of the sampling sites, box-plots with concentrations of 22 substances categorized per geographical area, residual diagnostics to assess model fit, the smoother of TOC, and spatial patterns for each substance. (PDF)

\section{AUTHOR INFORMATION}

\section{Corresponding Author}

*E-mail: gert.everaert@vliz.be.

\section{ORCID $\odot$}

Gert Everaert: 0000-0003-4305-0617

\section{Notes}

The authors declare no competing financial interest.

\section{ACKNOWLEDGMENTS}

The data for this study were gathered through the Norwegian contribution to the Joint Assessment and Monitoring Programme (JAMP), carried out by the Norwegian Institute for Water Research (NIVA) by contract from the Norwegian Environment Agency. Furthermore, we are grateful to the Institute of Marine Research (IMR) and the Geological Survey of Norway (NGU) for the use of the pollution data collected under the MAREANO program. G.E. is supported by a postdoctoral fellowship from the Special Research Fund of Ghent University (BOF15/PDO/061) in Belgium and received a FWO Travel Grant (V467215N) to stay at NIVA. This research contributes to the COCO project (grant no. 234 388) and is supported by the Norwegian Research Council. We thank the editor and four anonymous reviewers for their constructive comments, which helped us improve the quality of the manuscript.

\section{REFERENCES}

(1) OSPAR Quality Status Report 2010; OSPAR Commission: London, U.K., 2010; https://qsr2010.ospar.org/en/media/Chapter pdf/QSR complete EN.pdf.

(2) European Parliament. Directive 2000/60/EC of the European Parliament and of the Council of 23 October 2000 establishing a framework for Community action in the field of water policy. Official Journal L327, 1-73, 2000; European Parliament: Brussels, Belgium, 2000; http://eur-lex.europa.eu/legal-content/EN/TXT/HTML/?uri= CELEX:32000L0060\&from $=$ NL

(3) European Parliament. Directive 2008/56/EC of the European Parliament and of the Council of 17 June 2008 establishing a framework for community action in the field of marine environmental policy (Marine Strategy Framework Directive). Official Journal L164, 19-40, 2008; European Parliament: Brussels, Belgium, 2008; http:// eur-lex.europa.eu/legal-content/EN/TXT/HTML/?uri= CELEX:32008L0056\&from $=$ EN.

(4) International Council for the Exploration of the Sea. Report of the ICES advisory committee on fishery management and advisory committee on ecosystems; International Council for the Exploration of the Sea: Copenhagen, Denmark, 2004; http://www.ices.dk/sites/pub/ Publication\%20Reports/ICES\%20Advice/2004/Book1Part1.pdf.

(5) Office for Official Publications of the European Communities. Marine Strategy Framework Directive. Task Group 8 Report. Contaminants and pollution effects; JRC Scientific and Technical Reports; Office for Official Publications of the European Communities: Luxembourg,
Luxemburg, 2010; http://ec.europa.eu/environment/marine/pdf/7Task-Group-8.pdf.

(6) Weijs, L.; Covaci, A.; Yang, R. S. H.; Das, K.; Blust, R. A noninvasive approach to study lifetime exposure and bioaccumulation of PCBs in protected marine mammals: PBPK modeling in harbor porpoises. Toxicol. Appl. Pharmacol. 2011, 256, 136-145.

(7) Everaert, G.; De Laender, F.; Deneudt, K.; Roose, P.; Mees, J.; Goethals, P. L. M.; Janssen, C. R. Additive modelling reveals spatiotemporal PCBs trends in marine sediments. Mar. Pollut. Bull. 2014, 79, 47-53.

(8) Pozo, K.; Harner, T.; Lee, S. C.; Wania, F.; Muir, D. C.; Jones, K. C. Seasonally resolved concentrations of persistent organic pollutants in the global atmosphere from the first year of the gaps study. Environ. Sci. Technol. 2009, 43, 796-803.

(9) Cabrerizo, A.; Dachs, J.; Barcelo, D.; Jones, K. C. Climatic and biogeochemical controls on the remobilization and reservoirs of persistent organic pollutants in Antarctica. Environ. Sci. Technol. 2013, 47, 4299-4306

(10) Martins, M.; Costa, P. M.; Raimundo, J.; Vale, C.; Ferreira, A. M.; Costa, M. H. Impact of remobilized contaminants in Mytilus edulis during dredging operations in a harbour area: Bioaccumulation and biomarker responses. Ecotoxicol. Environ. Saf. 2012, 85, 96-103.

(11) Covelli, S.; Horvat, M.; Faganeli, J.; Brambati, A. Porewater distribution and benthic flux of mercury and methylmercury in the Gulf of Trieste (Northern Adriatic Sea). Estuarine, Coastal Shelf Sci. 1999, 48, 415-428.

(12) Nizzetto, L.; Gioia, R.; Li, J.; Pomati, F.; Bettinetti, R.; Dachs, J.; Jones, K. C.; Borga, K. Biological pump control of the fate and distribution of hydrophobic organic pollutants in water and plankton. Environ. Sci. Technol. 2012, 46, 3204-3211.

(13) Eckhardt, S.; Breivik, K.; Manoe, S.; Stohl, A. Record high peaks in PCB concentrations in the Arctic atmosphere due to long-range transport of biomass burning emissions. Atmos. Chem. Phys. 2007, 7, $4527-4536$

(14) Bogdal, C.; Schmid, P.; Zennegg, M.; Anselmetti, F. S.; Scheringer, M.; Hungerbühler, K. Blast from the past: melting glaciers as a relevant source for persistent organic pollutants. Environ. Sci. Technol. 2009, 43, 8173-8177.

(15) Schmid, P.; Bogdal, C.; Blüthgen, N.; Anselmetti, F. S.; Zwyssig, A.; Hungerbühler, $\mathrm{K}$. The missing piece: sediment records in remote mountain lakes confirm glaciers being secondary sources of persistent organic pollutants. Environ. Sci. Technol. 2011, 45, 203-208.

(16) O’Driscoll, K.; Ilyina, T.; Pohlmann, T.; Mayer, B.; Damm, P. Modelling the fate of persistent organic pollutants (POPs) in the North Sea system. Procedia Environ. Sci. 2011, 6, 169-179.

(17) Jartun, M.; Pettersen, A. Contaminants in urban runoff to Norwegian fjords. J. Soils Sediments 2010, 10, 155-161.

(18) Skei, J.; Price, N. B.; Calvert, S. E.; Holtedahl, H. The distribution of heavy metals in sediments of Sorfjord, West Norway. Water, Air, Soil Pollut. 1972, 1, 452-461.

(19) Skei, J. Dispersal and retention of pollutants in Norwegian fjords. Rapp. P.-v. Reun. Cons. Int. Explor. Mer. 1981, 181, 78-86.

(20) Ruus, A.; Green, N. W.; Maage, A.; Skei, J. PCB-containing paint and plaster caused extreme PCB-concentrations in biota from the Sørfjord (Western Norway) - a case study. Mar. Pollut. Bull. 2006, $52,100-103$

(21) Borgå, K.; Kidd, K. A.; Muir, D. C.; Berglund, O.; Conder, J. M.; Gobas, F. A.; Kucklick, J.; Malm, O.; Powell, D. E. Trophic magnification factors: considerations of ecology, ecosystems, and study design. Integr. Environ. Assess. Manage. 2012, 8, 64-84.

(22) Newman, M. C., Unger, M. A. Fundamentals of Eotoxicology; Lewis Publishers: Boca Raton, FL, 2003.

(23) Wood, S. N. Generalized Additive Models: An Introduction with R; CRC Press: Boca Raton, FL, 2006.

(24) Hastie, T.; Tibshirani, R. Generalized additive models. Statist. Sci. 1986, 3, 297-310.

(25) Feng, J.; Durant, J. M.; Stige, L. C.; Hessen, D. O.; Hjermann, D.Ø.; Zhu, L.; Llope, M.; Stenseth, N. C. Contrasting correlation 
patterns between environmental factors and chlorophyll levels in the global ocean. Glob. Biogeochem. Cycle 2015, 29, 2095-2107.

(26) Stenseth, N. C.; Llope, M.; Anadon, R.; Ciannelli, L.; Chan, K. S.; Hjermann, D.Ø.; Bagøien, E.; Ottersen, G. Seasonal plankton dynamics along a cross-shelf gradient. Proc. R. Soc. London, Ser. B 2006, 273, 2831-2838.

(27) Szöcs, E.; Brinke, M.; Karaoglan, B.; Schäfer, R. B. Large scale risks from agricultural pesticides in small streams. Environ. Sci. Technol. 2017, 51, 7378-7385.

(28) Rooper, C. N.; Zimmermann, M.; Prescott, M. M.; Hermann, A. J. Predictive models of coral and sponge distribution, abundance and diversity in bottom trawl surveys ofthe Aleutian Islands, Alaska. Mar. Ecol.: Prog. Ser. 2014, 503, 157-176.

(29) Orio, A.; Bergström, U.; Casini, M.; Erlandsson, M.; Eschbaum, R.; Hüssy, K.; Lehmann, A.; Ložys, L.; Ustups, D.; Florin, A. B. Characterizing and predicting the distribution of Baltic Sea flounder (Platichthys flesus) during the spawning season. J. Sea Res. 2017, 126, $46-55$.

(30) Gui, D.; Yu, R. Q.; Karczmarski, L.; Ding, Y.; Zhang, H.; Sun, Y.; Zhang, M.; Wu, Y. Spatiotemporal trends of heavy metals in IndoPacific humpback dolphins (Sousa chinensis) from the Western Pearl river estuary, China. Environ. Sci. Technol. 2017, 51, 1848-1858.

(31) Zuur, A. F.; Ieno, E. N., Walker, N. J., Saveliev, A. A., Smith, G. M. Mixed effects models and extensions in ecology with R; Springer Science+Business Media LLC: New York, U.S., 2009.

(32) Berrojalbiz, N.; Dachs, J.; Del Vento, S.; Ojeda, M. J.; Valle, M. C.; Castro-Jiménez, J.; Mariani, G.; Wollgast, J.; Hanke, G. Persistent organic pollutants in Mediterranean seawater and processes affecting their accumulation in plankton. Environ. Sci. Technol. 2011, 45, 43154322.

(33) R Development Core Team R. A language and environment for statistical computing; R Foundation for Statistical Computing: Vienna, Austria, 2015.

(34) Gomez-Gutierrez, A.; Garnacho, E.; Bayona, J. M.; Albaigés, J. Assessment of the Mediterranean sediments contamination by persistent organic pollutants. Environ. Pollut. 2007, 148, 396-408.

(35) Ma, Y.; Halsall, C. J.; Crosse, J. D.; Graf, C.; Cai, M.; He, J.; Gao, G.; Jones, K. C. Persistent organic pollutants in ocean sediments from the North Pacific to the Arctic Ocean. J. Geophys. Res. Oceans 2015, 120, 2723-2735.

(36) Suedel, B. C.; Boraczek, J. A.; Peddicord, R. K.; Clifford, P. A.; Dillon, T. M. Trophic transfer and biomagnification potential of contaminants in aquatic ecosystems. Rev. Environ. Contam. Toxicol. 1994, 136, 21-89.

(37) Sweetman, A. J.; Dalla Valle, M.; Prevedouros, K.; Jones, K. C. The role of soil organic carbon in the global cycling of persistent organic pollutants (POPs): interpreting and modelling field data. Chemosphere 2005, 60, 959-972.

(38) Palanques, A.; Diaz, J. L.; Farran, M. Contamination of heavy metals in the suspended and surface sediment of the Gulf of Cadiz (Spain): the role of sources, currents, pathways, and sinks. Oceanol. Acta 1995, 18, 469-477.

(39) Faust, J.; Knies, J.; Slagstad, T.; Vogt, C.; Milzer, G.; Giraudeau, J. Geochemical composition of Trondheimsfjord surface sediments: Sources and spatial variability of marine and terrigenous components. Cont. Shelf Res. 2014, 88, 61-71.

(40) Paetzel, M.; Nes, G.; Leifsen, L.Ø.; Schrader, H. Sediment pollution in the Vagen, Bergen harbour, Norway. Environ. Geol. 2003, 43, 476-483.

(41) Andersen, V.; Maage, A.; Johannessen, P. J. Heavy metals in blue mussel (Mytilus edulis) in the Bergen harbor area, western Norway. Bull. Environ. Contam. Toxicol. 1996, 57, 589-596.

(42) Mann, K. H., Lazier, J. R. N. Dynamics of marine ecosystems: Biological-physical interactions in the oceans; Blackwell Scientific Publications: Oxford, U.K., 1991.

(43) Saloranta, T. M.; Armitage, J. M.; Haario, H.; Naes, K.; Cousins, I. T.; Barton, D. N. Modeling the effects and uncertainties of contaminated sediment remediation scenarios in a Norwegian fjord by
Markov chain Monte Carlo simulation. Environ. Sci. Technol. 2008, 42, 200-206.

(44) Turner, A.; Millward, G. E. Suspended particles: their role in estuarine biogeochemical cycles. Estuarine, Coastal Shelf Sci. 2002, 55, 857-883.

(45) Temara, A.; Skei, J. M.; Gillan, D.; Warnau, M.; Jangoux, M.; Dubois, P. Validation of the asteroid Asterias rubens (Echinodermata) as a bioindicator of spatial and temporal trends of $\mathrm{Pb}, \mathrm{Cd}$, and $\mathrm{Zn}$ contamination in the field. Mar. Environ. Res. 1998, 45, 341-356.

(46) Reimann, C.; Banks, D.; Caritat, P.d. Impacts of airborne contamination on regional soil and water quality: the Kola Peninsula, Russia. Environ. Sci. Technol. 2000, 34, 2727-2732.

(47) Norwegian Institute for Air Research. Health and environmental impacts in the Norwegian border area related to local Russian industrial emissions; Norwegian Institute for Air Research: Kjeller, Norway, 2011; http://www.nilu.no/DesktopModules/NiluWeb.UserControls/ Resources/File.ashx?filename $=40$ - esh-norge-russlandgrenseomr\%C3\%A5der.pdf\&filetype=file.

(48) Rognerud, S.; Skotvold, T.; Fjeld, E.; Norton, S. A.; Hobæk, A. Concentrations of trace elements in recent and preindustrial sediments from Norwegian and Russian Arctic lakes. Can. J. Fish. Aquat. Sci. 1998, 55, 1512-1523.

(49) Norwegian Defence Research Establishment. Contamination from marine paints - a Norwegian perspective; Norwegian Defence Research Establishment: Kjeller, Norway, 1999; http://www.dtic.mil/ $\mathrm{dtic} / \mathrm{tr} /$ fulltext/u2/p010602.pdf.

(50) The National Institute of Nutrition and Seafood Research. Årsrapport 2011 Mattilsynets program: Fremmedstoffer $i$ villfisk med vekt på kystnare farvann: Delrapport I: Undersøkelser av miljøgifter $i$ taskekrabbe (in Norwegian); The National Institute of Nutrition and Seafood Research: Bergen, Norway, 2012; https://www.mattilsynet. no/mat og vann/uonskede stofferimaten/miljogifter/miljogifter_i t a s kekrabbe_2011.6024/binary/ Milj\%C3\%B8gifter\%20i\%20taskekrabbe\%202011.

(51) Norwegian Ministry of the Environment. Working together towards a non-toxic environment and a safer future - Norway's chemicals policy. Report No. 14 to the Storting; Norwegian Ministry of the Environment: Oslo, Norway, 2007; https://www.regjeringen.no/ contentassets/abe386e25e0e4d788e868d5f7f991362/en-gb/pdfs/ stm200620070014000en_pdfs.pdf.

(52) Norwegian Scientific Committee for Food Safety. Risk assessment of dietary cadmium exposure in the Norwegian population. Opinion of the Panel on Contaminants of the Norwegian Scientific Committee for Food Safety. Norwegian Scientific Committee for Food Safety: Oslo, Norway, 2015; https://zenodo.org/record/830602/ preview/643e411e5e.pdf.

(53) Norwegian Institute for Air Research. Relativ betydning av nasjonale metallutslipp i forhold til avsetning fra atmosfarisk langtransport og naturlige kilder (in Norwegian); Norwegian Institute for Air Research: Kjeller, Norway, 2003; http://www.miljodirektoratet.no/ old/klif/publikasjoner/overvaking/1950/ta1950.pdf.

(54) Everaert, G. Potential risk of organic micropollutants on marine phytoplankton in the greater North Sea: integration of modelling and experimental approaches. Ph.D Dissertation, Ghent University, Ghent, Belgium, 2015.

(55) De Laender, F.; Hammer, J.; Hendriks, A. J.; Soetaert, K.; Janssen, C. R. Combining monitoring data and modeling identifies PAHs as emerging contaminants in the Arctic. Environ. Sci. Technol. 2011, 45, 9024-9029.

(56) Friedman, C. L.; Selin, N. E. Long-range atmospheric transport of polycyclic aromatic hydrocarbons: A global 3-d model analysis including evaluation of Arctic sources. Environ. Sci. Technol. 2012, 46, 9501-9510.

(57) Dahle, S.; Savinov, V.; Petrova, V.; Klungsøyr, J.; Savinova, T.; Batova, G.; Kursheva, A. Polycyclic aromatic hydrocarbons (PAHs) in Norwegian and Russian Arctic marine sediments: concentrations, geographical distribution and sources. Norw. J. Geol. 2006, 86, 41-50.

(58) Boitsov, S.; Petrova, V.; Jensen, H.; Kursheva, A.; Litvinenko, I.; Klungsøyr, J. Sources of polycyclic aromatic hydrocarbons in marine 
sediments from southern and northern areas of the Norwegian continental shelf. Mar. Environ. Res. 2013, 87-88, 73-84.

(59) Kędra, M.; Renaud, P. E.; Andrade, H.; Goszczko, I.; Ambrose, W. G. Benthic community structure, diversity, and productivity in the shallow Barents Sea bank (Svalbard Bank). Mar. Biol. 2013, 160, 805819.

(60) Dalpadado, P.; Arrigo, K. R.; Hjøllo, S. S.; Rey, F.; Ingvaldsen, R. B.; Sperfeld, E.; van Dijken, G. L.; Stige, L. C.; Olsen, A.; Ottersen, G. Productivity in the Barents Sea - response to recent climate variability. PLoS One 2014, 9, e95273.

(61) Everaert, G.; De Laender, F.; Goethals, P.; Janssen, C. R. Multidecadal field data support intimate links between phytoplankton dynamics and PCB concentrations in marine sediments and biota. Environ. Sci. Technol. 2015, 49, 8704-8711.

(62) Tsapakis, M.; Apostolaki, M.; Eisenreich, S.; Stephanou, E. G. Atmospheric deposition and marine sedimentation fluxes of polycyclic aromatic hydrocarbons in the eastern Mediterranean basin. Environ. Sci. Technol. 2006, 40, 4922-4927.

(63) Castro-Jimenez, J.; Berrojalbiz, N.; Wollgast, J.; Dachs, J. Polycyclic aromatic hydrocarbons (PAHs) in the Mediterranean Sea: Atmospheric occurrence, deposition and decoupling with settling fluxes in the water column. Environ. Pollut. 2012, 166, 40-47.

(64) Gonzalez-Gaya, B.; Fernandez-Pinos, M. C.; Morales, L.; Méjanelle, L.; Abad, E.; Piña, B.; Duarte, C. M.; Jiménez, B.; Dachs, J. High atmosphere-ocean exchange of semivolatile aromatic hydrocarbons. Nat. Geosci. 2016, 9, 438-442.

(65) Ruus, A.; Green, N. W.; Maage, A.; Amundsen, C. E.; Schøyen, M.; Skei, J. Post World War II orcharding creates present day DDTproblems in The Sørfjord (Western Norway)-a case study. Mar. Pollut. Bull. 2010, 60, 1856-1861.

(66) Gioia, R.; Nizzetto, L.; Lohmann, R.; Dachs, J.; Temme, C.; Jones, K. C. Polychlorinated Biphenyls (PCBs) in air and seawater of the Atlantic Ocean: Sources, trends and processes. Environ. Sci. Technol. 2008, 42, 1416-1422.

(67) Jones, K. C.; de Voogt, P. Persistent organic pollutants (POPs): state of the science. Environ. Pollut. 1999, 100, 209-221.

(68) Sobek, A.; Gustafsson, O. Deep water masses and sediments are main compartments for Polychlorinated Biphenyls in the Arctic Ocean. Environ. Sci. Technol. 2014, 48, 6719-6725.

(69) Lepland, A.; Andersen, T. J.; Lepland, A.; Arp, H. P.; Alve, E.; Breedveld, G. D.; Rindby, A. Sedimentation and chronology of heavy metal pollution in Oslo harbor, Norway. Mar. Pollut. Bull. 2010, 60, 1512-1522.

(70) Eek, E.; Cornelissen, G.; Kibsgaard, A.; Breedveld, G. D. Diffusion of PAH and PCB from contaminated sediments with and without mineral capping; measurement and modelling. Chemosphere 2008, 71, 1629-1638.

(71) Cornelissen, G.; Pettersen, A.; Nesse, E.; Eek, E.; Helland, A.; Breedveld, G.D. The contribution of urban runoff to organic contaminant levels in harbour sediments near two Norwegian cities. Mar. Pollut. Bull. 2008, 56, 565-573.

(72) Nam, J. J.; Thomas, G. O.; Jaward, F. M.; Steinnes, E.; Gustafsson, O.; Jones, K. C. PAHs in background soils from Western Europe: Influence of atmospheric deposition and soil organic matter. Chemosphere 2008, 70, 1596-1602. 